\title{
A case of buried bumper syndrome in a patient with a balloon-tipped percutaneous endoscopic gastrostomy tube
}

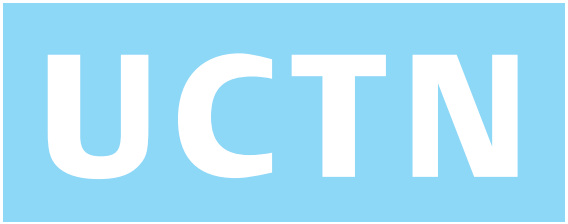

Buried bumper syndrome is a rare complication of percutaneous endoscopic gastrostomy (PEG) placement in which the internal bumper migrates from the gastric lumen and becomes lodged in the gastric wall or other places along the gastrostomy tract [1]. Most cases of buried bumper syndrome occur in patients with PEG tubes that have a mushroom-like round tip or a four-winged tip, as the relatively hard internal bumper causes pressure necrosis and results in buried bumper syndrome more frequently $[2,3]$. So far as we are aware, there have been no previous reports on buried bumper syndrome in patients with a balloon-tipped PEG tube. Since the fluid inside the balloon effectively regulates the pressure, the possibility of developing buried bumper syndrome is lower with a balloon-tipped tube $[2,3]$.

A 77-year-old woman was hospitalized for pain around a PEG tube that had developed 5 days previously. Her caregiver noticed a purulent discharge from the PEG insertion site. Thirteen months before, we had carried out a tube replacement and placed a balloon-tipped PEG tube. She was able to infuse the feeding formula through the tube by herself. There was food regurgitation through the PEG site during feeding. The caregiver reported that she had pulled the tube habitually whenever she felt that the feeding rate decreased. Around the PEG tube, a yellowish discharge and hyperemic granulation tissue were noticed (Figure $\mathbf{1}$ ), and a tender subcutaneous round mass was palpated. Abdominal computed tomography showed that the balloon was buried in the abdominal wall (Figure $\mathbf{2 a}$ ). At endoscopy, the internal bumper was not visible, but a small crevice with surrounding mucosal elevation was noted at the presumed site of insertion (Figure $\mathbf{2 b}$ ). The tube was cut below the balloon port and the water in the balloon was allowed to flow outside. It was then possible to pull out the buried PEG tube without difficulty.

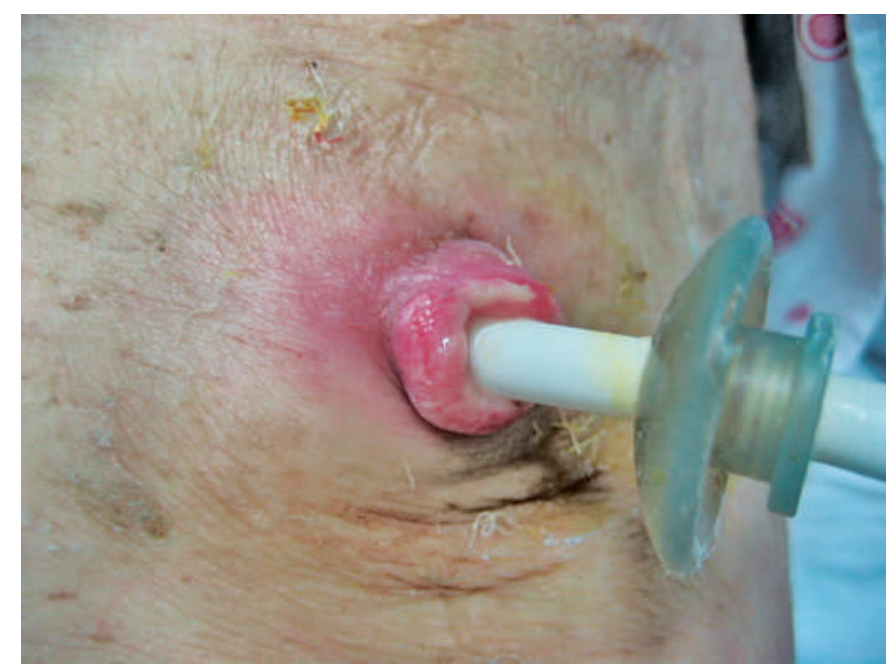

Figure 1 External view of the percutaneous endoscopic gastrostomy tube. A yellowish, thick, pus-like discharge around the percutaneous endoscopic gastrostomy (PEG) tube and granulation tissue with a surrounding hyperemic induration on PEG tube insertion site were noticed.

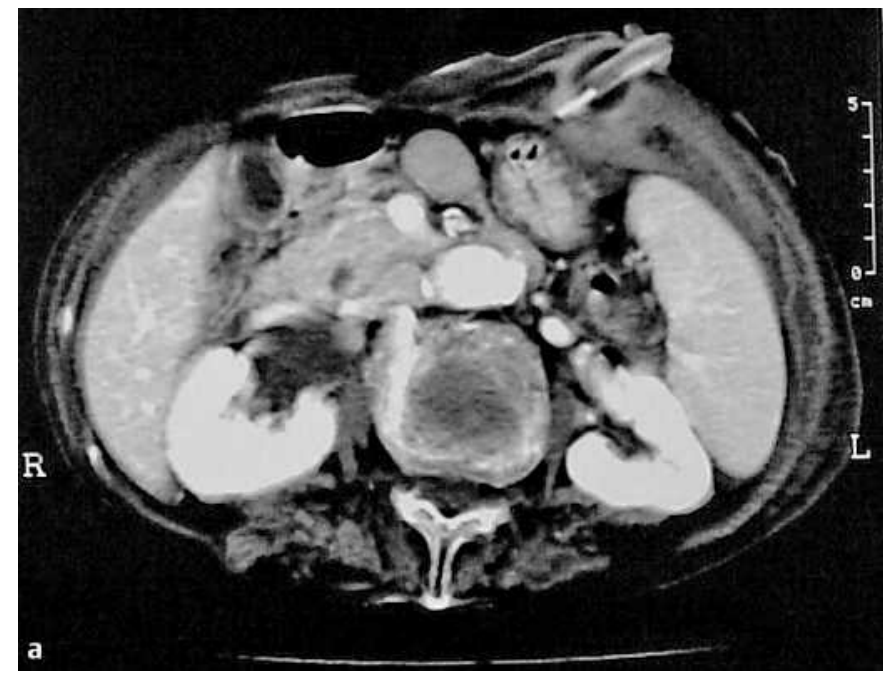

Figure 2 a Abdominal computed tomography, showing the balloon that was buried in the abdominal wall and thickening of the left lateral abdominal wall with infiltration, suggesting inflammation. b Nonvisualization of the internal bumper in the anterior wall of the lower gastric body. A small crevice with a surrounding mucosal elevation and yellowish discharge was noted at the presumed site of

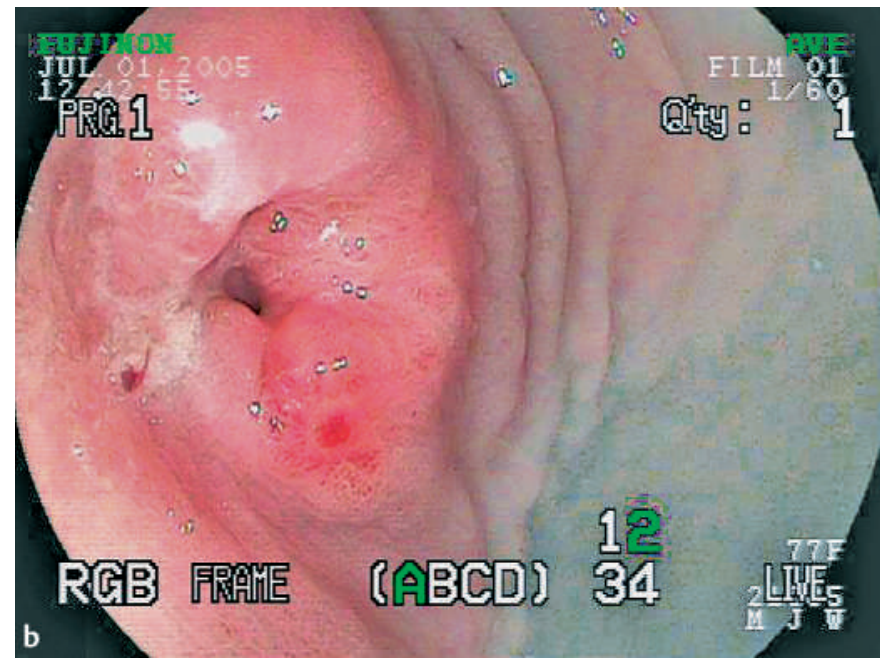
insertion. 


\section{UCTN}

This case suggests that excessive tension between the internal and external bumper is a more important factor for developing buried bumper syndrome than the type of internal bumper used.

\section{Acknowledgment}

Support for the preparation of this paper was received from Wonkwang University in 2004.

Endoscopy_UCTN_Code_CPL_1AH_2AI

Endoscopy_UCTN_Code_TTT_1AO_2AK
Y. S. Kim', Y. L. Oh', Y. W. Shon', H. D. Yang', S. I. Lee', E. Y. Cho', C. S. Choi ${ }^{1}$, G. S. Seo ${ }^{1}$, S. C. Choi ${ }^{1}$, Y.-H. Na ${ }^{1}$ ${ }^{1}$ Division of Gastroenterology, Dept. of Internal Medicine, Wonkwang University, Gunpo, South Korea

2 Dept. of Neurology, Wonkwang University, Gunpo, South Korea.

\section{References}

${ }^{1}$ Gauderer MW, Ponsky JL, Izant RJ Jr. Gastrostomy without laparotomy: a percutaneous endoscopic technique. J Pediatr Surg 1980; 15: $872-875$

2 Anagnostopoulos GK, Kostopoulos P, Arvanitidis DM. Buried bumper syndrome with a fatal outcome, presenting early as gastrointestinal bleeding after percutaneous endoscopic gastrostomy placement. J Postgrad Med 2003; 49: 325-327

${ }^{3}$ Gencosmanoglu R, Koc D, Tozun N. The buried bumper syndrome: migration of internal bumper of percutaneous endoscopic gastrostomy tube into the abdominal wall. J Gastroenterol 2003; 38: 1077-1080
Corresponding author

\section{Y. S. Kim, M.D.}

Division of Gastroenterology, Dept. of Internal Medicine Wonkwang University Sanbon Hospital Sanbon-dong 1142

Gunpo City

South Korea

Fax: $\quad+82-31-390-2244$

E-mail: wms89@hanmail.net 